\title{
Design and determination of stator geometry for axial flux permanent magnet free rod rotor synchronous motor
}

\author{
Osman Kalender ${ }^{\mathrm{a}}$, Yavuz Ege ${ }^{\mathrm{b}, *}$, Sedat Nazlibilek ${ }^{\mathrm{c}}$ \\ ${ }^{a}$ Turkish Military College, Department of Technical Sciences, 06100 Bakanliklar, Ankara, Turkey \\ ${ }^{\mathrm{b}}$ Balikesir University, Necatibey Faculty of Education, Department of Physics, 10100 Balikesir, Turkey \\ ${ }^{\mathrm{c}}$ Bilkent University, Nanotechnology Research Center (Nanotam), 06800 Ankara, Turkey
}

\section{A R T I C L E I N F O}

\section{Article history:}

Received 29 January 2011

Received in revised form 11 June 2011

Accepted 14 July 2011

Available online 27 July 2011

\section{Keywords:}

Synchronous motors

Rotating magnetic field

Stator

Rotor

Stirrer

\begin{abstract}
A B S T R A C T
During designing a new axial flux permanent magnet free rod rotor synchronous motor, it is important to know before hand in which phase the largest angular velocity can occur, what is the ways to reduce the power consumption, how to achieve to increase or decrease the rotation speed by changing the core geometry. Therefore, presenting these preliminary information that are necessary for the design of a free rod rotor synchronous motor to the researchers is the aim of this work. In this respect, this study presents the design and geometrical dimensions of the stator for a new synchronous motor which is an axial flux permanent magnet free rod machine with three, four, five and six phases. This type of motors are an innovative approach especially for the applications used in industrial stirrers. Each type of stator is designed such that it has an appropriate number of phases. The rotating magnetic field over the stator is established by a PIC based microcontroller feeding the interface circuit to the stator wounds. The maximum angular speeds of bar magnet rotors with four different lengths and masses are calculated theoretically and determined experimentally. In addition, the effects of the distance between the rotor and stator, the angular speed of the rotor within the limits of the operation, and the volume of the liquid to be stirred to the power applied are investigated. Furthermore, the effects of the lengths and angular speeds of the bar magnet rotors to the distance between the rotor and stator are determined. In the light of the information obtained and taking into account the power used, the most appropriate parameters and variables such as the stator geometry changing with the phase used, the length of rotor, the distance between the rotor and stator and the angular speeds of rotor are determined.
\end{abstract}

Crown Copyright @ 2011 Published by Elsevier Ltd. All rights reserved.

\section{Introduction}

Axial flux permanent magnet synchronous motors are suitable electrical machines for particular usage where small structures, high energy densities, high torques and limited axial fields are required. Axial flux permanent magnet synchronous motors are widely used in applications such as computer peripherals, small electrical vehicles and high momentum wheels [1-6].

\footnotetext{
* Corresponding author.

E-mail address: yavuzege@gmail.com (Y. Ege).
}

The free rod axial flux permanent magnet synchronous motors are electrical machines such that the rotor and stator are not physically connected but there is only a magnetic field between them [7-11].

In general, they are single pole machines with variable rotor lengths. This type of motor are generally used in applications for example stirring liquids, digging mines where no electrical arc is produced. They are also used in applications necessitating the physical separation of rotor and stator [12-19]. The number of phases and the power consumed, the distance of rotor-stator, maximum angular speed and also the density of liquid to be stirred play 

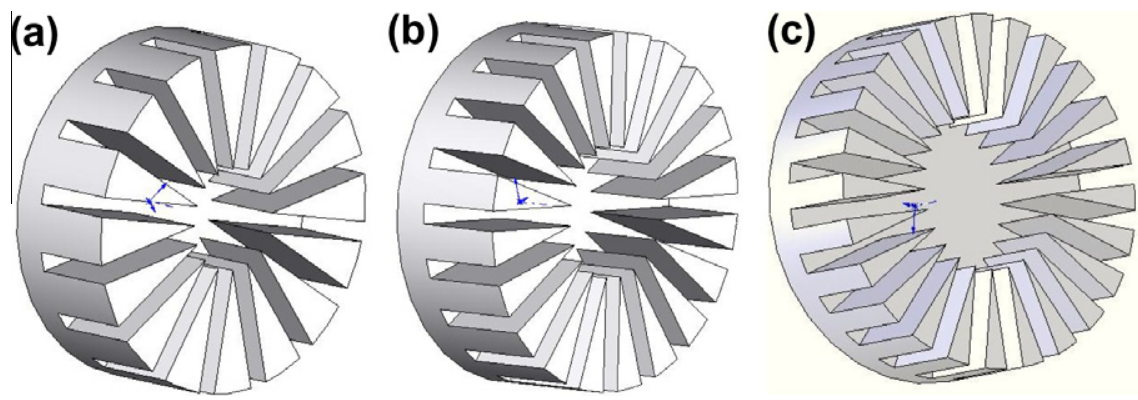

Fig. 1. The optimized stator structures for (a) four, (b) five and (c) six phase, axial flux permanent magnet free rod rotor synchronous motors.

important roles in the design of stator geometry of axial flux permanent magnet free rod rotor synchronous motors.

In this work, first, the stator geometries for three, four, five and six phase motors are determined and the systems are designed. Then, the phase circuits of each type of motors are fed by a PIC microcontroller in an appropriate manner in order to create the rotary magnetic field over the stators. Four different rotors with various lengths and masses are operated to determine their maximum angular speeds to be reached. Furthermore, the effects of the distances between the rotor and stator for different motors, the angular speeds and the density of the liquids used to the power consumed are investigated. In addition, the effects of the length and the angular speed of the rod magnet rotors to the rotorstator distances are determined. In light of the information obtained and also taking into account the power consumed, the followings are determined: the most appropriate geometry based on the phase, rotor length, the distance between the rotor and stator and rotor angular speed. All of these parameters, variables and structures are tried to optimize for designing the most appropriate motor structure for a particular or general application. Thus, the researchers (a)

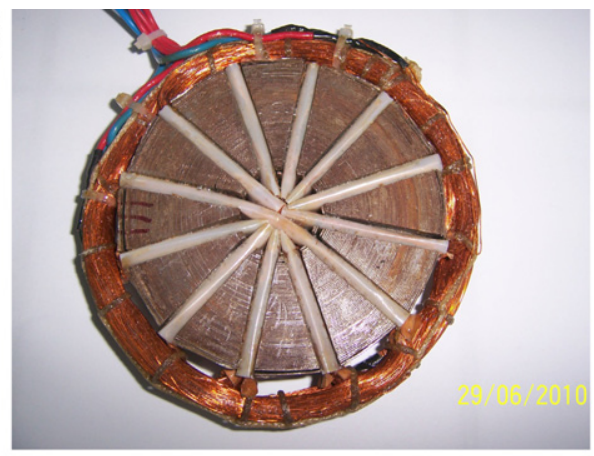

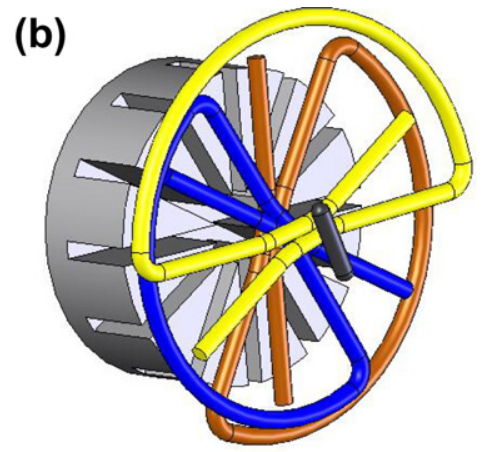

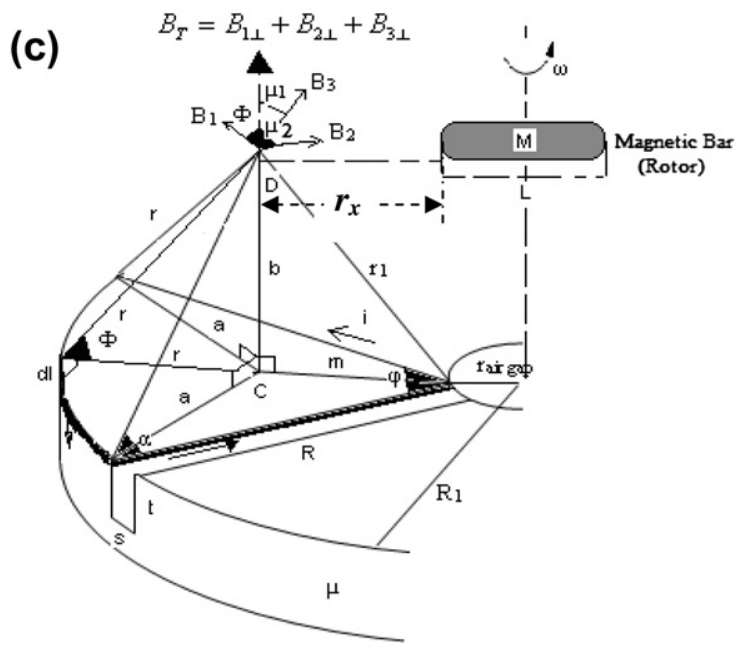

Fig. 2. For three-phase axial flux permanent magnet free rod rotor synchronous motor (a) stator structure, (b) wounds and (c) total magnetic field of one part. 


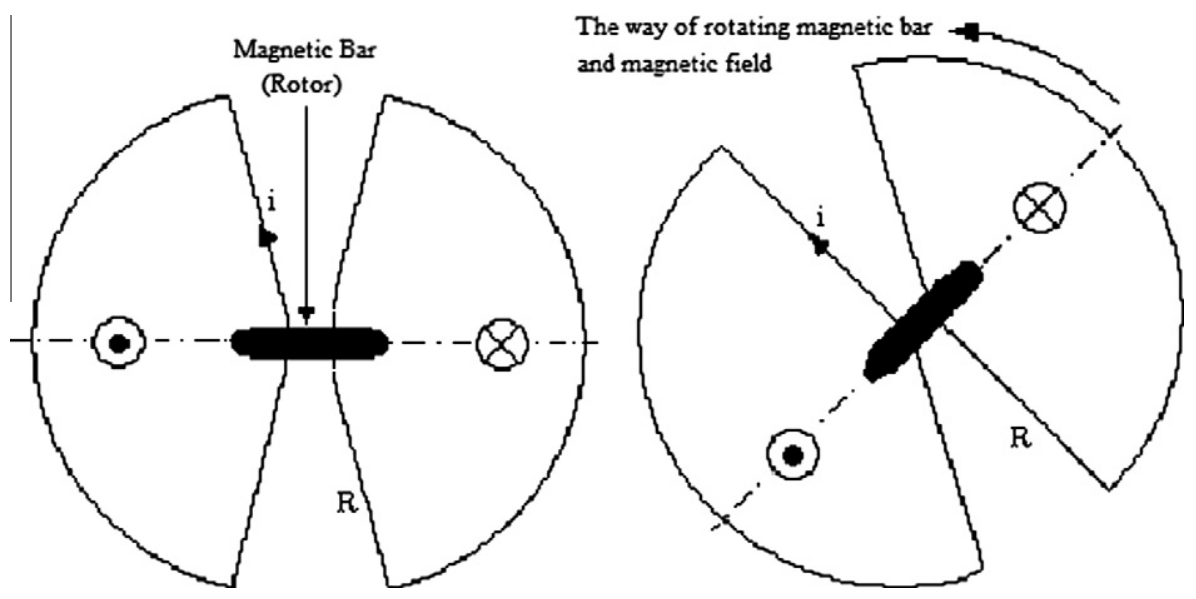

Fig. 3. The motion of the rotor with the rotation of the magnetic field.

Table 1

Parameter sets for motors with four different phases. ${ }^{\mathrm{a}}$

\begin{tabular}{|c|c|c|c|c|c|}
\hline Parameter & $\begin{array}{l}\text { Name of } \\
\text { parameter }\end{array}$ & 3 phase & 4 phase & 5 phase & 6 phase \\
\hline$m$ & Shown in Fig. 2 & $0.0247 \mathrm{~m}$ & $0.0236 \mathrm{~m}$ & $0.0213 \mathrm{~m}$ & $0.0135 \mathrm{~m}$ \\
\hline$\varphi$ & Angle of slice & $30^{\circ}$ & $22.5^{\circ}$ & $18^{\circ}$ & $15^{\circ}$ \\
\hline$R$ & Radius of slice & $0.0273 \mathrm{~m}$ & $0,02475 \mathrm{~m}$ & $0.02221 \mathrm{~m}$ & $0.01968 \mathrm{~m}$ \\
\hline$s$ & Groove width & $0.005 \mathrm{~m}$ & & & \\
\hline$t$ & Groove depth & $0.020 \mathrm{~m}$ & & & \\
\hline$n$ & $\begin{array}{l}\text { Diameter of coil } \\
\text { wire }\end{array}$ & $0.0004 \mathrm{~m}$ & & & \\
\hline$a$ & Shown in Fig. 2 & $0.0143 \mathrm{~m}$ & $0.0133 \mathrm{~m}$ & $0.0118 \mathrm{~m}$ & $0.01018 \mathrm{~m}$ \\
\hline$R_{1}$ & $\begin{array}{l}\text { Radius of stator } \\
\text { disk }\end{array}$ & $0.050 \mathrm{~m}$ & & & \\
\hline$k$ & $\begin{array}{l}\text { Number of } \\
\text { phases }\end{array}$ & 3 & 4 & 5 & 6 \\
\hline$B$ & $\begin{array}{l}\text { Magnetic field } \\
\text { of rotor }\end{array}$ & \multicolumn{4}{|c|}{$0.621 \times 10^{3} \mathrm{~T}(1) / 0.702 \times 10^{3} \mathrm{~T}(2) / 0.894 \times 10^{3} \mathrm{~T}(3) / 0.964 \times 10^{3} \mathrm{~T}(4)$} \\
\hline$r_{x}$ & Shown in Fig. 2 & $0.0157 \mathrm{~m}(\mathrm{~T} 1) 0.0127 \mathrm{~m}(\mathrm{~T}$ & $0.0168 \mathrm{~m}(\mathrm{~T} 1) 0.0138 \mathrm{~m}(\mathrm{~T}$ & $0.0163 \mathrm{~m}(\mathrm{~T} 1) 0.0131 \mathrm{~m}(\mathrm{~T}$ & $0.0163 \mathrm{~m}(\mathrm{~T} 1) 0.0133 \mathrm{~m}(\mathrm{~T}$ \\
\hline & & $\begin{array}{l}\text { 2) } 0.0085 \mathrm{~m}(\mathrm{~T} 3) 0.0056 \mathrm{~m} \\
(\mathrm{~T} 4)\end{array}$ & $\begin{array}{l}\text { 2) } 0.0098 \mathrm{~m}(\mathrm{~T} \mathrm{3}) 0.0065 \mathrm{~m} \\
(\mathrm{~T} 4)\end{array}$ & $\begin{array}{l}\text { 2) } 0.0092 \mathrm{~m}(\mathrm{~T} \mathrm{3}) 0.0053 \mathrm{~m} \\
\text { (T 4) }\end{array}$ & $\begin{array}{l}\text { 2) } 0.0094 \mathrm{~m}(\mathrm{~T} 3) 0.0054 \mathrm{~m} \\
(\mathrm{~T} 4)\end{array}$ \\
\hline$M$ & Mass of rotor & \multicolumn{4}{|c|}{$0.00212 \mathrm{~kg}(\mathrm{~T} 1) / 0.00274 \mathrm{~kg}(\mathrm{~T} 2) / 0.00371 \mathrm{~kg}(\mathrm{~T} 3) / 0.00441 \mathrm{~kg}(\mathrm{~T} 4)$} \\
\hline$L$ & Length of rotor & \multicolumn{4}{|c|}{$20 \mathrm{~mm}(\mathrm{~T} 1) / 30 \mathrm{~mm}$ (T 2)/40 mm (T 3)/70 mm (T 4) } \\
\hline$\mu$ & $\begin{array}{l}\text { Magnetic } \\
\text { permeability }\end{array}$ & \multicolumn{4}{|c|}{$0.008792 \mathrm{~T} \mathrm{~m} / \mathrm{A}$} \\
\hline$r_{i}$ & $\begin{array}{l}\text { Internal radius } \\
\text { of stator }\end{array}$ & $0.0125 \mathrm{~m}$ & $0.0144 \mathrm{~m}$ & $0.01521 \mathrm{~m}$ & $0.02132 \mathrm{~m}$ \\
\hline
\end{tabular}

a (T 1), (T 2), ( ( 3), and (T 4) stands for the rotor types as type 1, type 2, type 3 and type 4 respectively.

doing the design of such a synchronous motor would be able to determine simply in which phase the largest angular velocity can occur, what is the ways to reduce the power consumption, how to achieve to increase or decrease the rotation speed by changing the core geometry. In this paper, Section 2 describes the structure of the motor and rotating magnetic field. In Section 3, the parameters for an optimized structure are given. Section 4 gives the details of the experimentations and findings.

\section{Structure of the motor and rotating magnetic field}

The optimized stator structures for four, five and six phase, axial flux permanent magnet free rod rotor synchronous motors are illustrated in Fig. 1.
As seen in Fig. 1, there are four slices for each phase. The radius of the central region of the core increases as the number of phases increase. In Fig. 2a and b, the stator structure and the shape of the wounds of a three-phase axial flux permanent magnet free rod rotor synchronous motor are shown. The rotor will follow the rotary magnetic field created over the stator by the microcontroller with a phase angle of $120^{\circ}$ between each phases. The angular speed of the rotor will be equal to that of the magnetic field. As a matter of fact, the capability of rotation of the rotor with the angular speed of the magnetic field is also depended on the magnitude of the kinetic energy initially gained by the rotor itself. If the kinetic energy gained by the rotor from the magnetic field is less than the rotational kinetic energy of the rotor, then the rotor cannot follow the vector of the rotary magnetic filed and as a result it will 
driven away. In such a case, the angular speed gained by the rotor will be limited. This limit depends on the magnitude of the magnetic field created at the point, D, of the axial flux permanent magnet free rod rotor synchronous motor as seen in Fig. 2c where the rotor angular speed is $\omega$, the length of rotor is $L$, the magnetic flux density is $B$, the internal radius od iron core stator is $r_{i}$, the rad $r_{i}$,ius of stator iron core is $R_{1}$, the magnetic permeability of the iron core is $\mu$, the depth of groove is $t$, the widht of groove

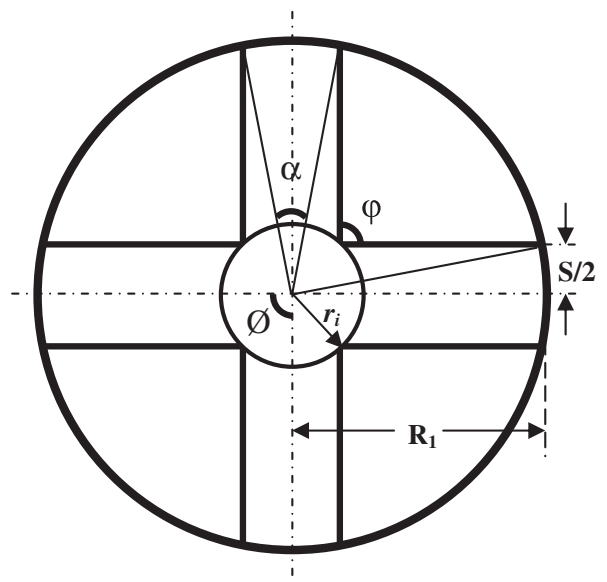

Fig. 4. Single phase stator core.

(a)

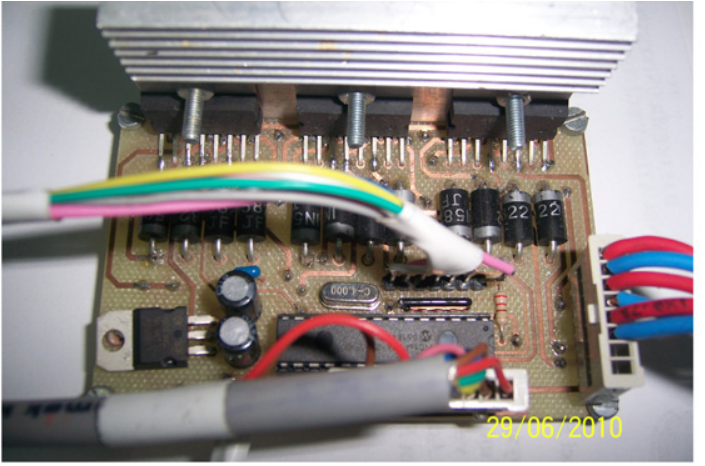

(b)

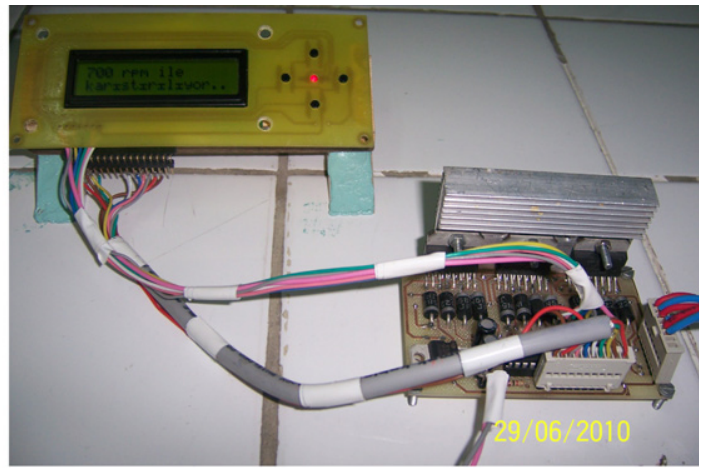

(c)

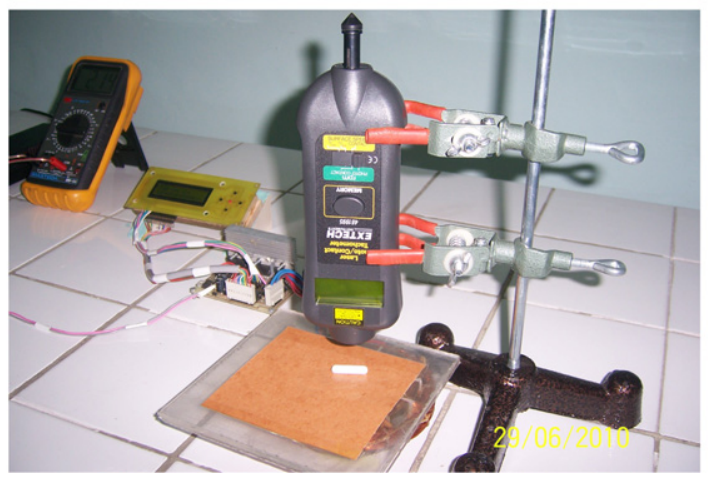

is $s$. The distances $a, b, m, r, R, r_{x}$, the point $C$ and the angles $\phi, \varphi, \alpha$ are depicted in Fig. 2c.

As seen in Fig. 2c, the magnetic field effecting the rotation of the rotor at the point $D$ is equal to the sum of the perpendicular components of magnetic fields of the two wires with a length of $R$ and the perpendicular component of the arc with a degree of $\varphi[20]$.

$B_{T}=\left(4 k \frac{s t}{n^{2}}\right)\left(B_{1 \perp}+B_{2 \perp}+B_{3 \perp}\right)$

When the rotor is located at such a magnetic field, it comes to the direction of the filed with the effect of the magnetic torque. When the rotary magnetic field takes an angle of $\varphi$ the rotor will follow it simultaneously. Fig. 3 shows the motion of the rotor with the rotation of the magnetic field.

It can be thought that the rotation of the rotor becomes more stable when the number of phases is increased. However, this is not the case. Since the parameters effecting the total magnetic field are also changing with the increase in number of phases. The optimum number of phases for various types of stators is changing as well.

In order a rotor to rotate at the axis on which the center of mass is found without driven away, the angular speed $\omega$ has to satisfy the condition given in the following equation [20]:

$\omega \leqslant \sqrt{\frac{48 B\left(4 k \frac{s t}{n^{2}}\right)\left(B_{1 \perp}+B_{2 \perp}+B_{3 \perp}\right) r_{\chi}^{2} \cos \varphi}{M L}}$ (d)

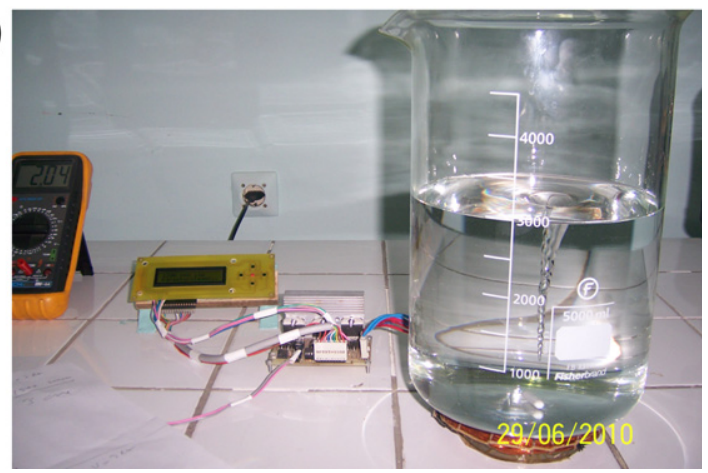

Fig. 5. (a) Microcontroller interface unit, (b) stopping, operating and speed adjustment panel, (c) rotor angular speed measurement setup and (d) magnetic stirring operation. 
Table 2

Maximum angular speed values measured and calculated for different rotors and number of phases.

\begin{tabular}{|c|c|c|c|c|c|c|c|c|}
\hline \multirow[t]{2}{*}{ Rotor type } & \multicolumn{2}{|c|}{$\omega(k=3)(\mathrm{rpm})$} & \multicolumn{2}{|c|}{$\omega(k=4)(\mathrm{rpm})$} & \multicolumn{2}{|c|}{$\omega(k=5)(\mathrm{rpm})$} & \multicolumn{2}{|c|}{$\omega(k=6)(\mathrm{rpm})$} \\
\hline & Measured & Calculated & Measured & Calculated & Measured & Calculated & Measured & Calculated \\
\hline 1 & 2021 & 2016.85 & 2187 & 2182. 19 & 1983 & 1985.23 & 1904 & 1895.68 \\
\hline 2 & 1505 & 1494.87 & 1625 & 1608.34 & 1473 & 1457.22 & 1426 & 1413.59 \\
\hline 3 & 1104 & 1093.31 & 1177 & 1172.81 & 1078 & 1076.54 & 1041 & 1034.32 \\
\hline 4 & 453 & 445.27 & 482 & 478.45 & 438 & 432.65 & 418 & 411.43 \\
\hline
\end{tabular}

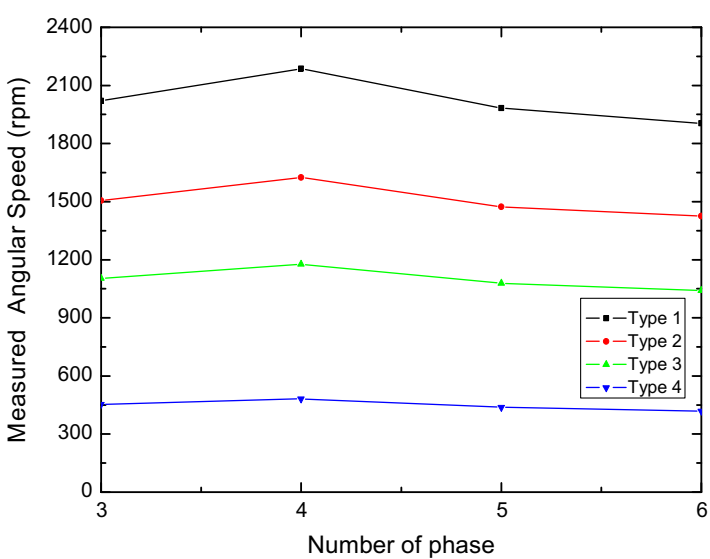

Fig. 6. Measured angular speed with respect to number of phases.

As seen from Eq. (2), the angular speed of rotor depends on the parameters such as the magnitude of the rotor magnetic field, mass and length, the number of phases of the stator, groove dimensions of the stator, phase current, the distance $r_{x}$ shown in Fig. 2c and $\cos \varphi^{\prime}$. The parameter sets for the motors produced with four different phases is given in Table 1.

\section{Structure of stator iron core}

In this section, the structure of the stator iron core is investigated. Let's look at in detail the stator core of a single phase stator for the effects of the distance $r_{x}$ and the angle $\phi$ to the angular speed (Fig. 4).

For the arc in Fig. 4, it can be written as,

$$
S=a R_{1}
$$

It can be noticed that each of the slices is reduced by $\alpha$ because of the widths of the grooves. Two grooves are created on the disk for each phase wounded as half steps. For the number of phases $k=1$, the arc $\phi$ becomes as in the following equation:

$\varphi=\varnothing-\alpha=\frac{\pi}{2 k}-\frac{s}{R_{1}}$

Assuming $s \ll 2 \pi R_{1}$; it can be written as

$$
\begin{aligned}
& s / 2=r_{i} \sin (\varnothing / 2) \\
& r_{i}=\frac{s / 2}{\sin (\pi / 4 k)}
\end{aligned}
$$

As seen from Eq. (5) that the internal radius of the stator $r_{i}^{\prime}$ does not increase in directly proportional to the number of phases $k$. The external radius $R_{1}$ of the iron core in which the stator wounds are embedded and the width of grooves limit the number of phases. In this work, the external radius of stator iron core is $R_{1}=50 \mathrm{~cm}$, groove width is $s=5 \mathrm{~mm}$ and maximum number of phases is $k=15$ (Eq. (4)). Because for $k=15$, the angle $\varphi=0$, that is, there is no pie slice on the core in this case.

After defining the internal radius of the stator $r_{i}$, the distance shown in Fig. 2c, $r_{x}$, can be written as;

$$
\begin{aligned}
& r_{x}=\left(m+r_{i}\right)-L / 2 \\
& r_{x}=\left(m+\frac{s}{2 \sin (\pi / 4 k)}\right)-\frac{L}{2}
\end{aligned}
$$

Using Eq. (6), we can arrange Eq. (2) as follows;

$$
\omega \leq\left|\frac{48 B\left(4 k \frac{s t}{n^{2}}\right)\left(B_{11}+B_{21}+B_{31}\right)\left(\left(m+\frac{s}{\sin (\pi / 4 k)}\right)-\frac{L}{2}\right)^{2} \cos \varphi}{M L}\right|^{1 / 2}
$$

Eq. (7) includes all the necessary parameters for dimensioning and designing of an axial flux permanent magnet free rod rotor synchronous motor.

\section{Experimental study and findings}

The experimental study and findings are presented in this section The universal interface unit providing supply signal waveforms for motors with phases from three to six is shown in Fig. 5a and b. The PIC16F876 microcomputer sends the triggering signals to the driver integrated circuit (IC) corresponding to the angular velocities in rpm that are entered from the touch-pad. Output of the driver IC is fed to the coils of the stirrer. Currents up to $3 \mathrm{~A}$ can flow through the coils. In the experimental step of the study, first of all, we checked that whether the reading of number of rotations in the interface display and the readings in the tachometer optically measuring the angular speed of the rotor are equal to each other or not (Fig. 5c). Then loss of rotation due to the friction within the liquid is investigated. It is seen that the measurements give satisfactory results and the effect of friction is negligible. Fig. $5 \mathrm{~d}$ illustrates the stirring operation.

In the next step, the maximum angular speeds of rod magnet rotors with four different lengths and masses rotating over the stator are determined. For this test, the number of rotations are increased through the interface unit until the rotor is driven away. Then, the same results 


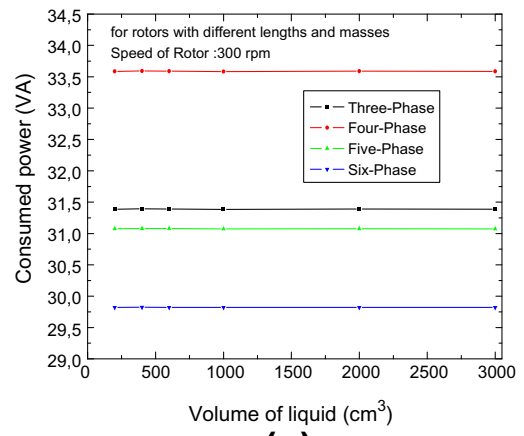

(a)

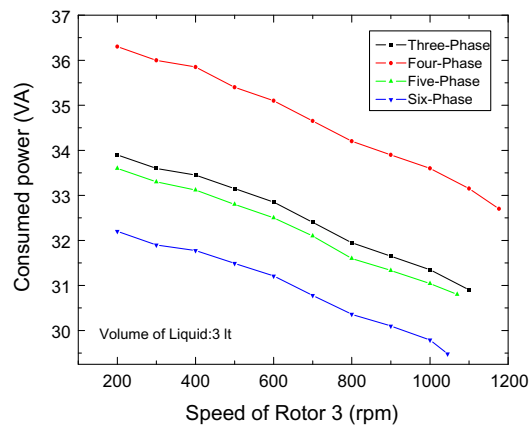

(d)

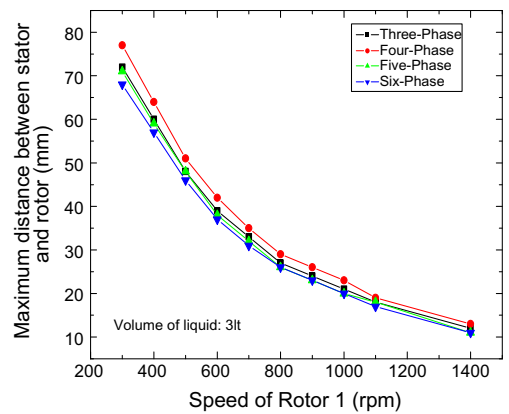

(g)

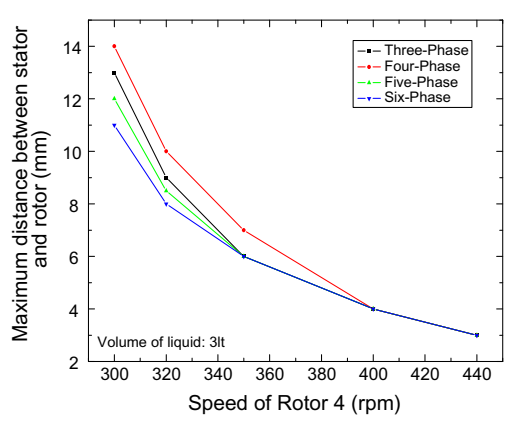

(j)

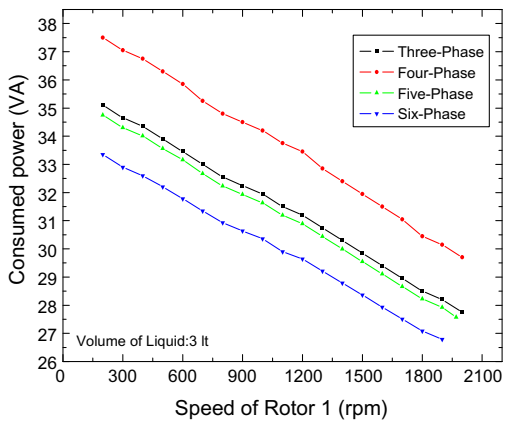

(b)

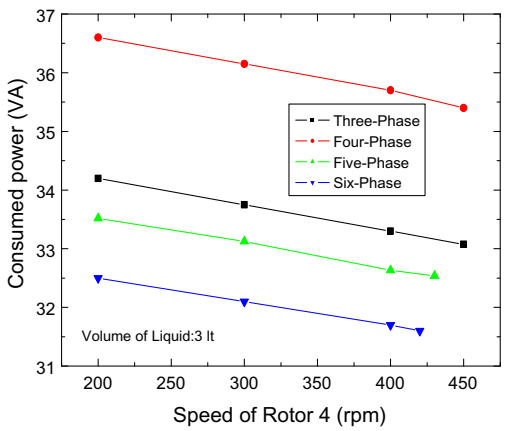

(e)

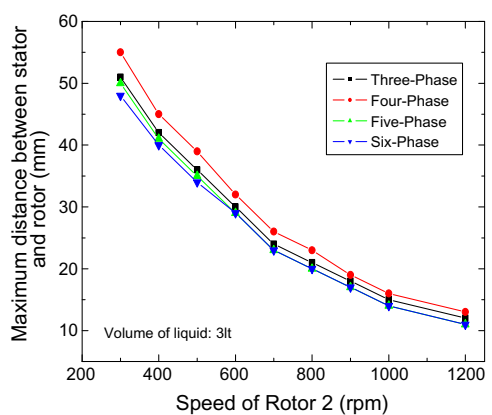

(h)

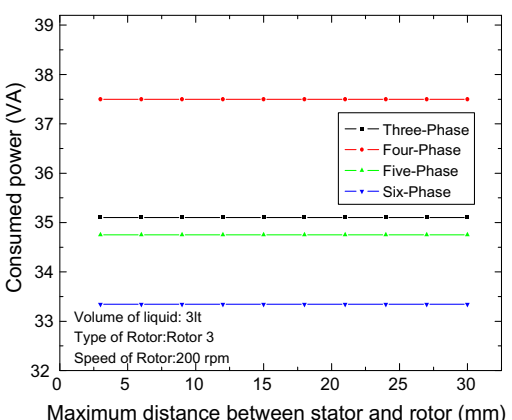

(k)

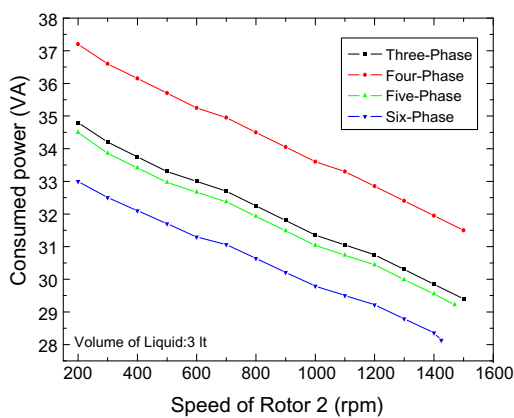

(c)

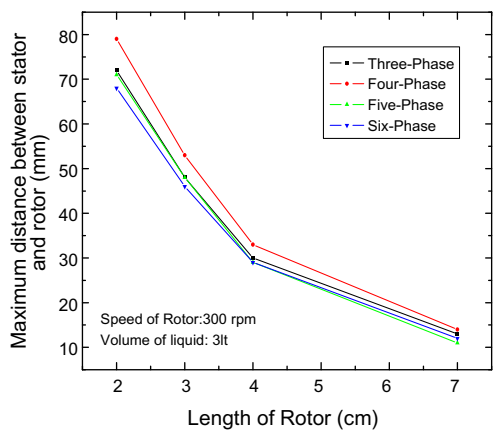

(f)

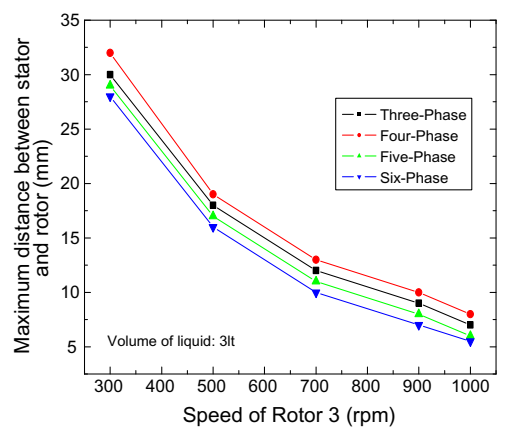

(i)

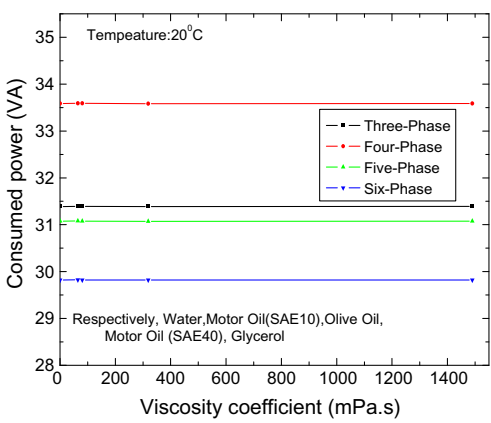

(m)

Fig. 7. Graphics for a three-four-five and six phase axial flux permanent magnet free rod rotor synchronous motor are shown.

are obtained by using the parameters in Table 1 and Eq. (7) theoretically. It is observed that both practical and theoretical findings are matched satisfactorily (Table 2). It is ob- served from the maximum number of rotations with respect to number of phases measured for each rotor that the highest angular speed is achieved for $k=4$ (Fig. 6). 
In addition, the effect of the distance between rotor and stator, rotor angular speed within operational limits and the volume of the liquid stirred for different stator geometries to the power consumed are determined. For this case, the distance between the rotor and stator is increased gradually. This is done until the effect of the rotary magnetic field on the rotor ceased and at each step the current drawn is read by the ammeter. And then, by fixing the distance between rotor and stator, the volume of the liquid is increased with the steps of $200 \mathrm{~cm}^{3}$ and again the currents drawn at each step are recorded.

Next, the effects of length of the rod magnet rotors and angular speed values to the distance between the rotor and stator are determined. For this experiment, the angular speed is fixed for four different lengths of rotor and the distance is increase away. And then, for each rotor, the angular speed is increased step by step and for each step of speed, the rotor-stator distance is changed until the rotor is not affected by the rotary magnetic field. The results are plotted as graphics (Fig. 7). With the use of these results and taking into account the power consumption, the stator geometry, rotor length, rotor-stator distance and rotor angular speed values are determined.

As seen from Fig. 7a, the increase in volume of the liquid to be stirred does not change the power consumption. This shows that the pressure acting on the rotor does not have any relation with the angular speed or angular frequency. Since, the angular frequency is only changed by means of the microcontroller interface unit and the rotor follows the magnetic field with the same frequency. The relation between the angular frequency and the circuit current determining the power is given in the following equation $[21,22]$.

$i=\frac{V_{0}}{\sqrt{(w \times L)^{2}+r_{0}^{2}}}$

where $V_{0}$ is the constant supply voltage, $L$ is the self inductance, $r_{0}$ is the internal resistance of the wire of the wounds. The self inductance is given in the following equation:

$L=\frac{\mu \times N^{2} \times A}{l}$

where $\mu$ is the magnetic permeability of the stator core, $N$ is the number of turns, $A$ is the cross section of the wounds and $l$ is the length of the wound. As seen in Eqs. (8) and (9), the current, and therefore the power are based on the variables determining the self inductance and angular frequency. The liquid pressure may effect the motion of the rotor but may not be any direct relation with the angular frequency and the power. With the similar reasoning, the coefficient of viscosity does not change the power consumed (Fig. $7 \mathrm{~m}$ ).

The graphics in Fig. 7b-e show that the power is decreasing as the speed of rotor is increasing. The reason for it is that the total impedance is increasing and the current drawn is decreasing.

The graphics in Fig. $7 \mathrm{f}-\mathrm{j}$ show that the increase in length and angular speed of the rotor decrease the distance be- tween rotor and stator. The reason for it is that the force acting on the rotor decreases as a result of increase in angular frequency and decrease in magnetic field effect. When the magnetic field effect is decreased and the centrifugal force effect become dominant, the rotor tends to fly away. This may happen even in more small rotor-stator distances.

As seen in the graphics in Fig. 7k, there is no relation between the rotor-stator distance and the power consumption. Since the power consumed depends on the current drawn, self inductance and angular frequency. Therefore, the power drawn will stay constant for the distances where the stirring action takes place.

The observations listed in Table 2 show that the largest value among the maximum angular speeds occur when the number of phases is $k=4$. When we increase and decrease the number of phases, the maximum angular speed values decrease in both cases. If the number of phases increases, then the rotor change its position with smaller $\varphi$ angles. This can be considered as a more stable motion. However, when the $\varphi$ angles decrease, the $r_{i}$ distances increase and depending on this the $r_{x}$ distances and the angular speeds reached can decrease.

\section{Conclusion}

In this study, the design and geometrical dimensions of the stator for a synchronous motor which is an axial flux permanent magnet free rod machine with three, four, five and six phases is implemented. This type of motors are an innovative approach especially for the applications used in industrial stirrers. The mathematical model developed is proven by the experiments and tests done on a practically implemented and operated motors The following conclusions are reached:

1. The largest angular speed can be achieved with a 4-phase machine;

2. In order to decrease the power consumption, it is necessary to operate the motor with low speeds;

3. There is no relation between the volume and viscosity coefficient of the liquid to be stirred and power consumption and number of phases;

4. The rotor-stator distance decreases with the increase in rotor speed and the motor has to be operated in low speeds when the rotor-stator distance is large;

5. The distance of rotor-stator is not related to the power consumption and the number of phases;

6. For high angular speeds, the rotor length should be small;

7. The radius of internal stator iron core $r_{i}$ should be less than or equal to the smallest rotor length, and the number of phases and the external radius of the iron core should be determined taking into account this result;

8. The magnetic field of a rod magnet rotor may affect the maximum angular speed to be reached; and

9. The number of turns of the wound and the thickness of the wire used can affect the maximum angular speed to be reached. 


\section{References}

[1] P. Kurronen, J. Pyrhonen, Analytic calculation of axial-flux permanent-magnet motor torque, IEEE Transactions on Electric Power Applications IET 1 (January) (2007) 59-63.

[2] F. Caricchi, F.G. Capponi, F. Crescimbini, L. Solero, Experimental study on reducing cogging torque and no-load power loss in axial-flux permanent-magnet machines with slotted winding, IEEE Transactions on Industry Applications 40 (July-August) (2004) 1066-1075.

[3] B.J. Chalmers, E. Spooner, An axial-flux permanent-magnet generator for a gearless wind energy system, IEEE Transactions on Energy Conversion 14 (June) (1999) 251-257.

[4] M. Aydin, Surong Huang, T.A. Lipo, Torque quality and comparison of internal and external rotor axial flux surface-magnet disc machines, IEEE Transactions on Industrial Electronics 53 (3) (2006) 822-830.

[5] H. Nakai, H. Ohtani, E. Satoh, Y. Inaguma, Development and testing of the torque control for the permanent-magnet synchronous motor, IEEE Transactions on Industrial Electronics 52 (3) (2005) 800806.

[6] M. Pacas, J. Weber, Predictive direct torque control for the PM synchronous machine, IEEE Transactions on Industrial Electronics 52 (5) (2005) 1350-1356.

[7] A.H. Wijenayake, J.M. Bailey, P.J. McCleer, Design optimization of an axial gap permanent magnet brushless DC motor for electric vehicle applications, in: Thirtieth Conference Industrial Application, IAS'95, vol. 1, October 1995, pp. 685-692.

[8] D. Patterson, R. Spee, The design and development of an axial flux permanent magnet brushless DC motor for wheel drive in a solar powered vehicle, IEEE Transaction on Industrial Applications 31 (5) (1995) 1054-1061.

[9] G.H. Jang, J.H. Chang, Development of an axial-gap spindle motor for computer hard disk drives using PCB winding and dual air gaps, IEEE Transaction on Magnetics 38 (5) (2002) 1054-1061.

[10] F. Sahin, A.M. Tuckey, A.J. Vandenput, Design, development and testing of a high speed axial-flux permanent-magnet machine, in: Thirtieth-Sixth Conference Industrial Application, IAS'2001, vol. 3, September-October 2001, pp. 1640-1647.
[11] Y. Ege, O. Kalender, S. Nazlıbilek, Electromagnetic stirrer operating in double axis, IEEE Transactions on Industrial Electronics 57 (7) (2010) 2444-2453.

[12] M. Rashed, P.F.A. MacConnell, A.F. Stronach, P. Acarnley, Sensorless indirect-rotor-field-orientation speed control of a permanentmagnet synchronous motor with stator-resistance estimation, IEEE Transactions on Industrial Electronics 54 (3) (2007) 1664-1675.

[13] J.-L. Shi, T.-H. Liu, Y.-C. Chang, Position control of an interior permanent-magnet synchronous motor without using a shaft position sensor, IEEE Transactions on Industrial Electronics 54 (4) (2007) 1989-2000.

[14] Z. Xu, F. Rahman, An adaptive sliding stator flux observer for a direct-torque-controlled IPM synchronous motor drive, IEEE Transactions on Industrial Electronics 54 (5) (2007) 2398-2406.

[15] K.-Y. Lian, C.-H. Chiang, H.-W. Tu, LMI-based sensorless control of permanent-magnet synchronous motors, IEEE Transactions on Industrial Electronics 54 (5) (2007) 2769-2778.

[16] P. Beccue, S. Pekarek, Using torque-ripple-induced vibration to determine the initial rotor position of a permanent magnet synchronous machine, IEEE Transactions on Power Electronics 21 (3) (2006) 818-821.

[17] M.A. Mueller, A.S. McDonald, D.E. Macpherson, Structural analysis of low-speed axial-flux permanent-magnet machines, IEEE Transactions on Electric Power Applications 152 (November) (2005) 1417-1426.

[18] J.R. Bumby, R. Martin, M.A. Mueller, E. Spooner, N.L. Brown, B.J. Chalmers, Electromagnetic design of axial-flux permanent magnet machines, IEEE Transactions on Electric Power Applications 151 (March) (2004) 151-160.

[19] J. Azzouzi, G. Barakat, B. Dakyo, Analytical modeling of an axial flux permanent magnet synchronous generator for wind energy application, in: 2005 IEEE International Conference on Electric Machines and Drives, May 2005, pp. 1255-1260.

[20] O. Kalender, Y. Ege, A PIC microcontroller based electromagnetic stirrer, IEEE Transactions on Magnetics 43 (9) (2007) 3579-3585.

[21] O. Gurdal, Elektromanyetik Alan Teorisi, Nobel Press, Ankara, Turkey, 2000.

[22] E. Gunduz, Modern fizige giris, Ege University, Press of the Faculty of Science, Izmir, Turkey, 1993. 